\title{
SISTEM APLIKASI LOWONGAN KERJA LULUSAN MAHASISWA CIC PADA UNIVERSITAS CATUR INSAN CENDEKIA KOTA CIREBON BERBASIS WEBSITE I
}

\author{
Indrayansyah $^{1}$, Linda Norhan $^{2}$, Wiwiek Nurkomala Dewi ${ }^{3}$ \\ Universitas Catur Insan Cendekia \\ Jl. Kesambi No. 202, Cirebon \\ e-mail: indrayansyah15@gmail.com ${ }^{1}$, linda.norhan@cic.ac.id ${ }^{2}$,wiwiek.nurkomala.dewi@cic.ac.id ${ }^{3}$
}

\begin{abstract}
ABSTRAK
Pada saat ini lulusan mahasiswa Universitas Catur Insan Cendekia masih memiliki kendala dalam hal mencari pekerjaan, yaitu lulusan mahasiswa masih mencari informasi lowongan pekerjaan yang disediakan oleh sentra karir di mading-mading kampus ataupun informasi melalui media sosial. Dalam proses pembuatan sistem tersebut dimulai dengan tahapan analisa sistem. Kemudian pemodelan proses digambarkan menggunakan Flowmap, Use Case Diagram, Class Diagram, Activity Diagram dan Sequence Diagram dengan menggunakan metode waterfall. Hal ini memudahkan lulusan mahasiswa dalam pembuatan Curriculum Vitae karena sudah tersedianya form pengisian yang dapat secara otomatis menjadi CV. Terdapat juga media yang dapat menyimpan portofolio lulusan mahasiswa sehingga dapat mempermudah perusahaan dalam melihat profil kandidat lulusan mahasiswa. Lulusan mahasiswa juga dapat melamar pekerjaan langsung melalui website tersebut. Serta perusahaan dapat mencari, melihat profil lulusan mahasiswa, serta mengajak kandidat lulusan mahasiswa untuk bergabung.
\end{abstract}

Kata kunci: Sistem, Lowongan, Pekerjaan, Lulusan, CIC

\begin{abstract}
At this time, Catur Insan Cendekia University student graduates still have problems in terms of finding a job, namely student graduates are still looking for job vacancies provided by career centers on campus wall magazine or information via social media. $n$ the process of making the system, it begins with the system analysis stage. Then the process modeling is described using Flowmaps, Use Case Diagrams, Class Diagrams, Activity Diagrams and Sequence Diagrams using the waterfall method. Make it easy for graduate students to make Curriculum Vitae because there is already a filling form that can automatically become a CV. There are also media that can store student graduate portfolios so that it can make it easier for companies to view profiles of student graduate candidates. Student graduates can also apply for jobs directly through the website. Companies can also search, view student graduate profiles, and invite graduate student candidates to join.
\end{abstract}

Keywords: System, Vacancies, Job, Graduates, CIC

\section{Pendahuluan}

Perkembangan teknologi pada saat ini berkembang begitu pesat, hampir segala aspek kehidupan manusia menggunakan teknologi. Dalam bidang informasi, perkembangan teknologi telah memberikan dampak yang cukup berarti dalam meningkatkan kegiatan berbagai sarana informasi, khususnya dalam hal memberikan kemudahan kepada lulusan mahasiswa Universitas CIC dengan adanya informasi lowongan kerja yang disediakan oleh kampus. Oleh karena itu berdasarkan uraian diatas, penyusun merasa tertarik untuk mengambil judul "Sistem Aplikasi Lowongan Kerja Lulusan Mahasiswa CIC Pada Universitas

Sistem Aplikasi Lowongan Kerja Lulusan Mahasiswa CIC Pada Universitas Catur Insan Cendekia Kota Cirebon Berbasis Website I - (Indrayansyah, Linda Norhan, Wiwiek Nurkomala Dewi) 
Catur Insan Cendekia Kota Cirebon Berbasis Website" dengan tujuan agar dapat memecahkan masalah yang timbul di Universitas CIC tersebut.

\section{KAJIAN PUSTAKA}

\subsection{Sistem}

Untuk mengawali pembahasan tentang analisis dan perancangan sistem informasi, pemahaman akan sistem terlebih dahulu harus ditekankan. Definisi sistem perkembangan sesuai dengan konteks dimana pengertian sistem digunakan. Dari beberapa definisi sistem secara umum, dapat disimpulkan bahwa sistem adalah sekumpulan komponen atau jaringan kerja dari prosedur-prosedur yang saling berkaitan dan saling bekerja sama membentuk suatu jaringan kerja untuk mencapai sasaran atau tujuan tertentu (Muhamad Muslihudin dan Oktafianto, 2016: 1-3).

\subsection{Teknologi}

Teknologi adalah cara di mana kita menggunakan ilmu pengetahuan untuk memecahkahkan masalah praktis (Tuti Andriani, 2015; 132-133).

\subsection{Website}

Website merupakan sejumlah halaman web yang memiliki topik saling terkait antara halaman yang satu dengan halaman yang lain, terkadang disertai pula dengan gambar, video, animasi, atau jenis-jenis objek lainnya. Sebuah website biasanya ditempatkan setidaknya pada sebuah server web yang dapat diakses melalul jaringan seperti internet, ataupun jaringan wilayah lokal (LAN) melalui alamat internet yang dikenali sebagai URL (Uniform Resource Locator). Gabungan atas semua website yang dapat diakses publik di internet disebut pula sebagai World Wide Web atau lebih dikenal dengan singkatan WWW. Dengan website, tujuan perusahaan ataupun pebisnis perorangan dapat dicapai dengan efektif dan efisien (Yeni Susilowati, 2019; 36-37).

\subsection{Database}

Basis data sebuah kumpulan data yang saling berhubungan secara logis, dan merupakan sebuah pejelasan dari data tersebut, yang didesain untuk menemukan data yang dibutuhkan oleh banyak departemen dan pemakai. Didalam basis data, semua data diintegrasikan dengan menghindari duplikasi data. Basis data juga merupakan sekumpulan elemen data terintegrasi yang secara logika saling berhubungan. Basis data mengonsolidasikan berbagai catatan yang terlebih dahulu disimpan dalam file-file terpisah ke dalam satu gabungan umum elemen data yang menyediakan data untuk banyak aplikasi. Elemen data yang menyediakan data untuk banyak aplikasi. Elemen data mendiskripsikan entitas-entitas dan hubungan antara entitas-entitas tersebut (Indrajani, 2015; 70).

\subsection{UML}

Unified Modeling Language selanjutnya disebut UML adalah sebuah teknik pengembangan sistem yang menggunakan bahasa grafis sebagai alat untuk pendokumentasian dan melakukan spesifikasi pada sistem. Standar UML dikelolah oleh Object Management Group (OMG). UML yang akan kita bahas disini, hanya empat diagram yang akan kita gunakan yaitu Use Case Model (memiliki 3 diagram) dan Activity Diagram (Muhamad Muslihudin dan Oktafianto, 2016; 58-59).

\section{METODE PENELITIAN}

Kerangka penelitian adalah urutan yang akan dilakukan dalam suatu penelitian. Agar langkah-langkah yang diambil penulis dalam perancangan ini tidak melenceng dari pokok pembicaraan dan lebih mudah dipahami, maka urutan langkah-langkah penelitian akan dibuat secara sistematis dan dapat digunakan sebagai pedoman yang jelas serta mudah untuk menyelesaikan permasalahan yang ada. Urutan langkahlangkah yang akan dibuat pada penelitian ini dapat dilihat pada gambar berikut ini: 


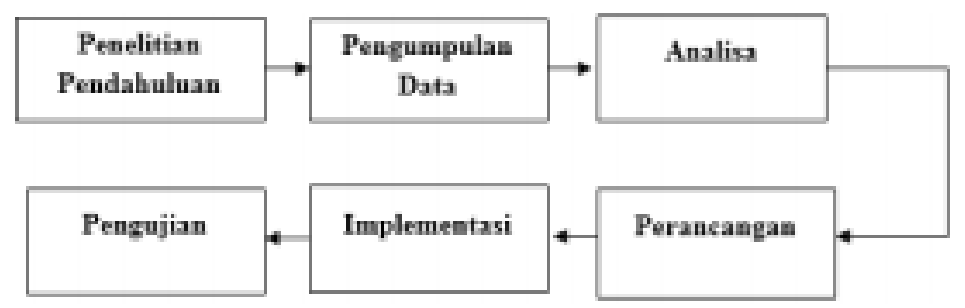

Gambar 1. Metode Penelitian (Aldo, Dasril et al. 2019)

\section{HASIL DAN PEMBAHASAN}

\subsection{Perancangan Flowmap Komputerisasi}

\subsubsection{Login User Lulusan}

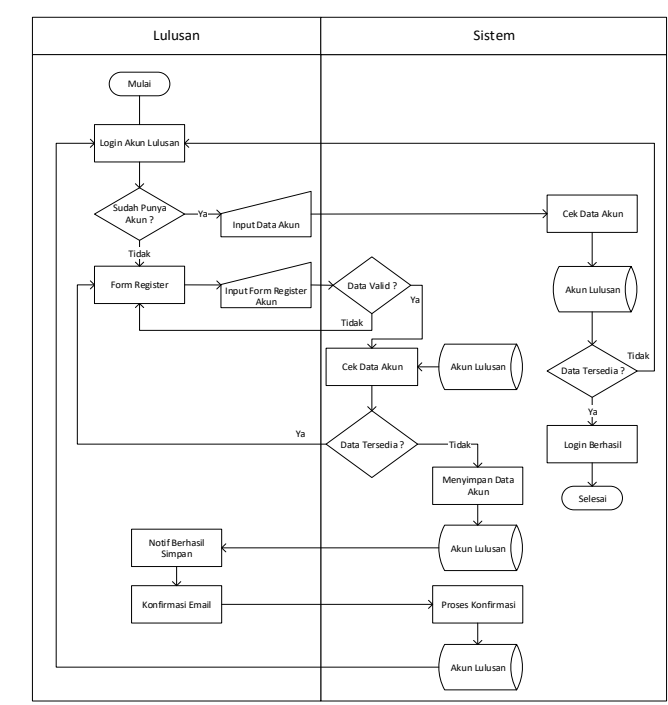

Gambar 2. Flowmap Komputerisasi Login User Lulusan Mahasiswa

\subsubsection{Login User Perusahaan}

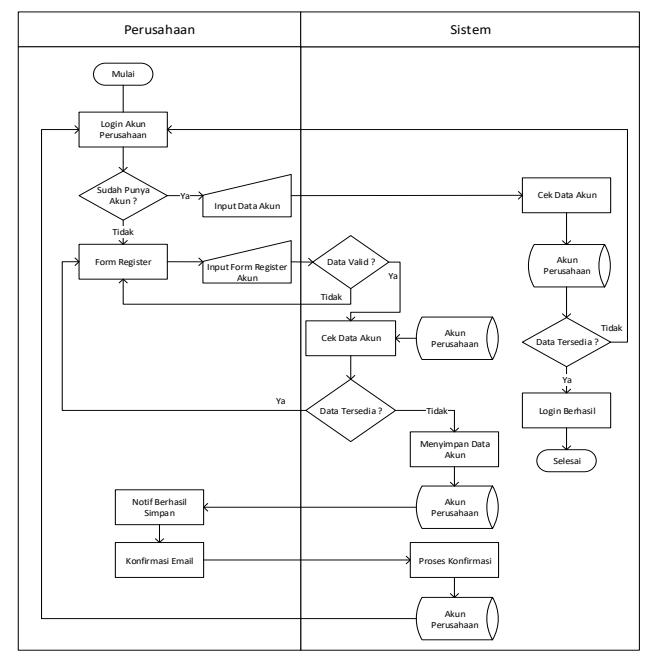

Gambar 3. Flowmap Komputerisasi Login User Perusahaan

Sistem Aplikasi Lowongan Kerja Lulusan Mahasiswa CIC Pada Universitas Catur Insan Cendekia Kota

Cirebon Berbasis Website I - (Indrayansyah, Linda Norhan, Wiwiek Nurkomala Dewi) 
4.1.3 Melengkapi Data Akun Lulusan Mahasiswa

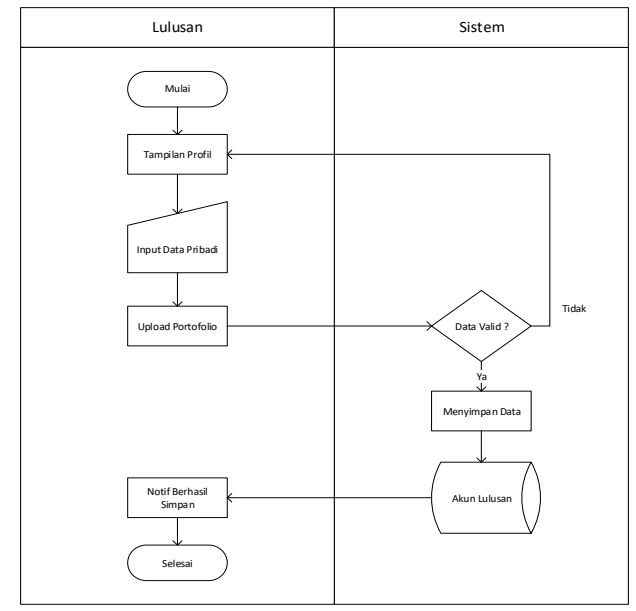

Gambar 4. Flowmap Komputerisasi Melengkapi Data Akun Lulusan Mahasiswa

\subsection{Perancangan Desain}

\subsubsection{Use Case Diagram}

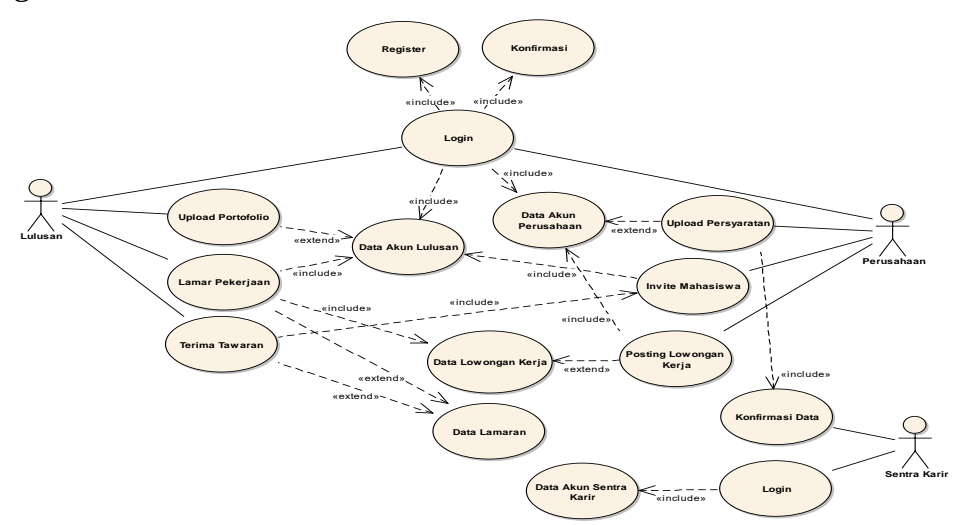

Gambar 5. Use Case Diagram

\subsubsection{Class Diagram}

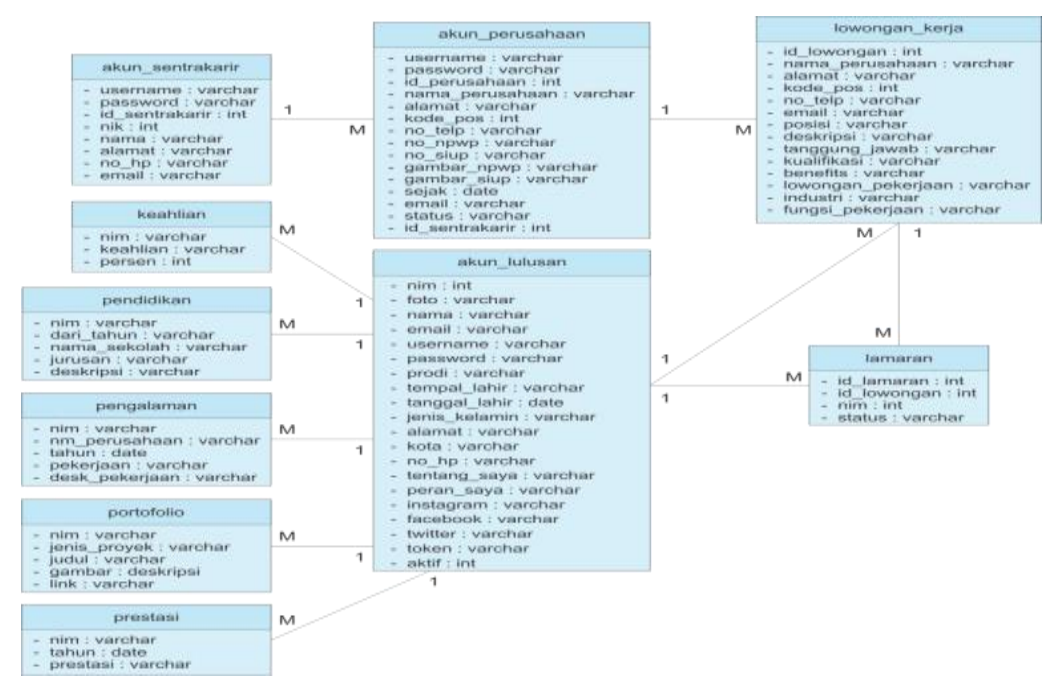

Gambar 6. Class Diagram 


\subsubsection{Activity Diagram}

\subsubsection{Login User}

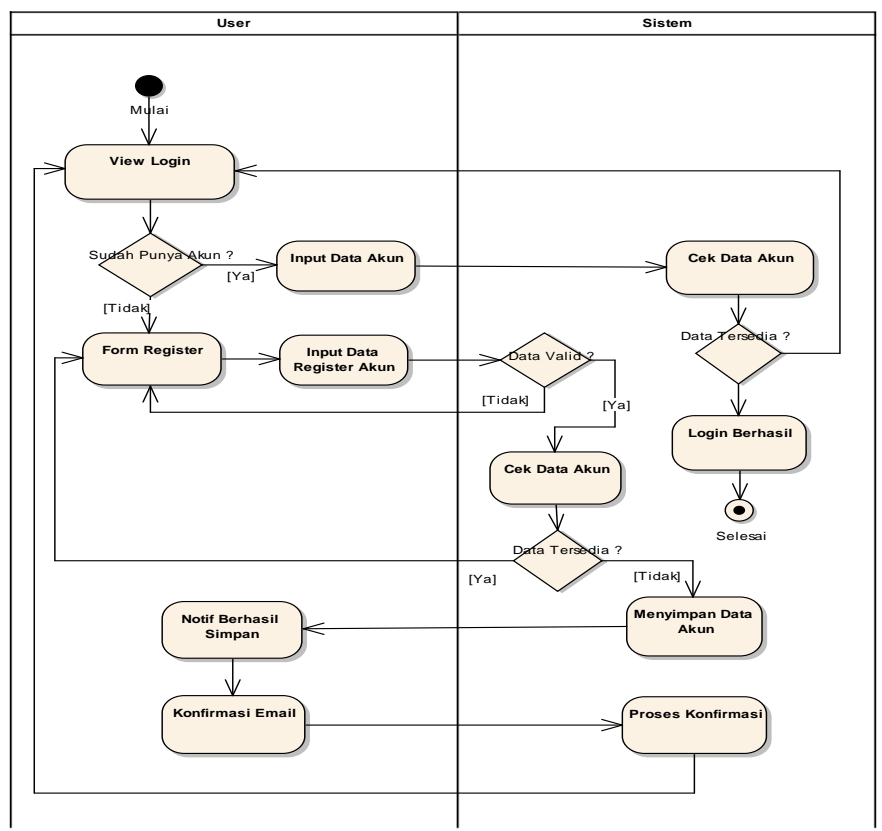

Gambar 7. Activity Diagram Login User

\subsubsection{Melengkapi Data Akun Lulusan Mahasiswa}

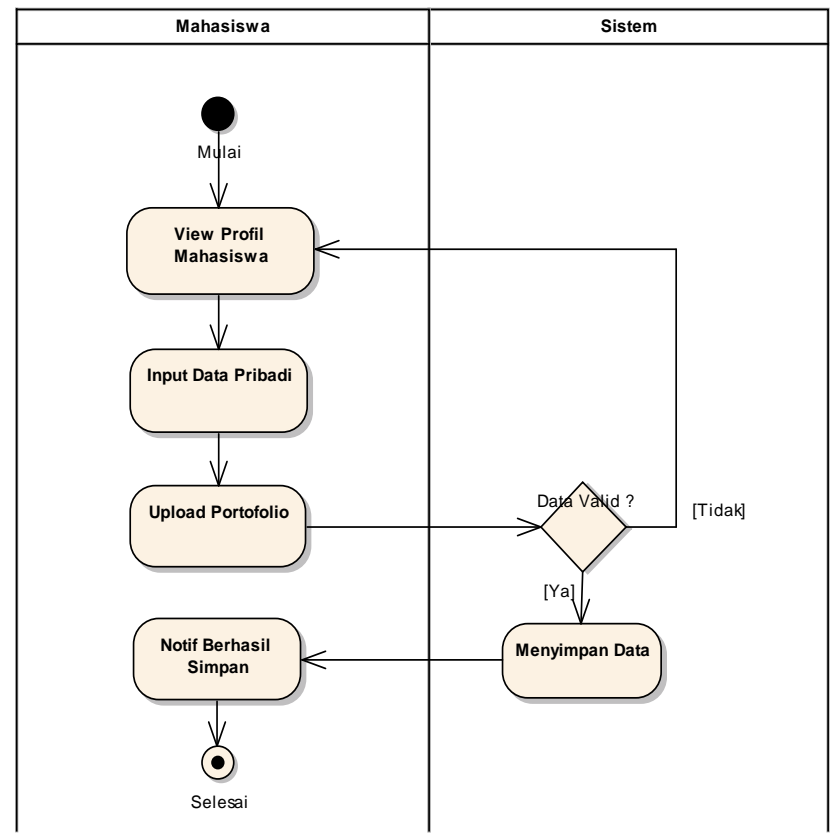

Gambar 8. Activity Diagram Melengkapi Data Akun Mahasiswa

Sistem Aplikasi Lowongan Kerja Lulusan Mahasiswa CIC Pada Universitas Catur Insan Cendekia Kota Cirebon Berbasis Website I - (Indrayansyah, Linda Norhan, Wiwiek Nurkomala Dewi) 
4.2.3.3 Melengkapi Data Akun Perusahaan

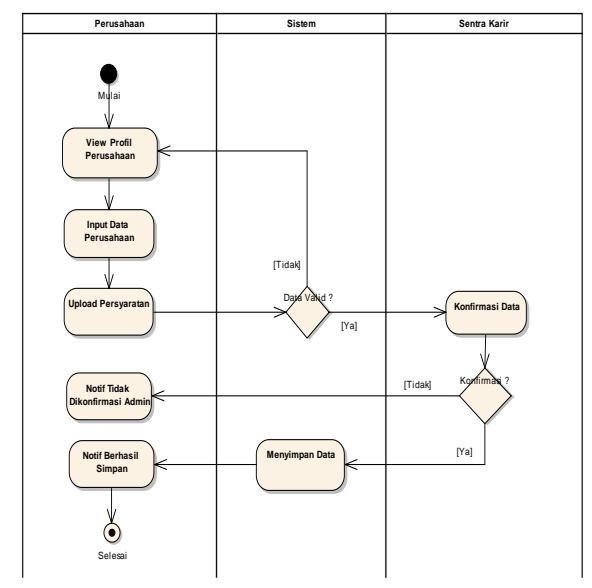

Gambar 9. Activity Diagram Melengkapi Data Akun Perusahaan

\subsection{Sequence Diagram}

\subsubsection{Login User Mahasiswa}

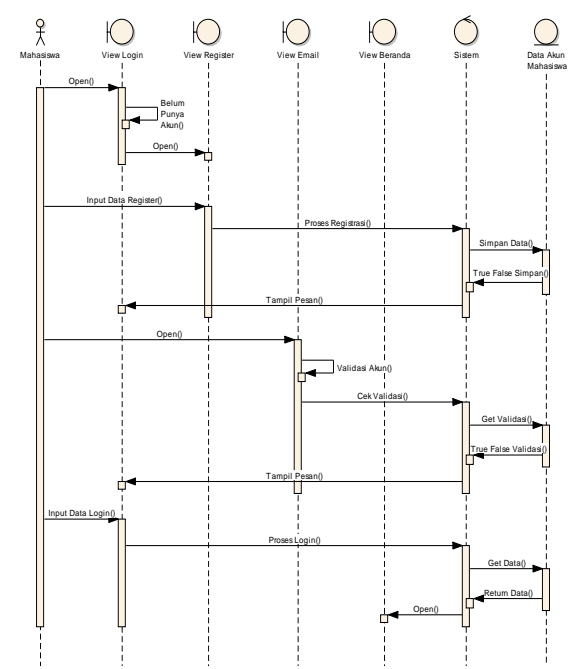

Gambar 10. Sequence Diagram Login User Mahasiswa

4.3.2 Login User Perusahaan

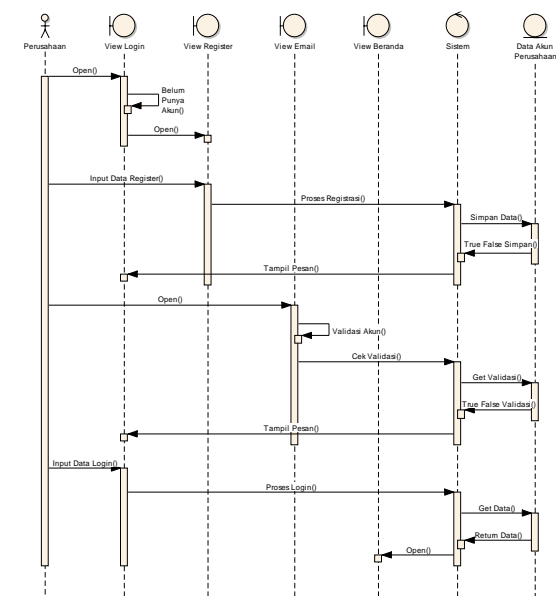

Gambar 11. Sequence Diagram Login User Perusahaan 


\subsubsection{Melengkapi Data Akun Mahasiswa}

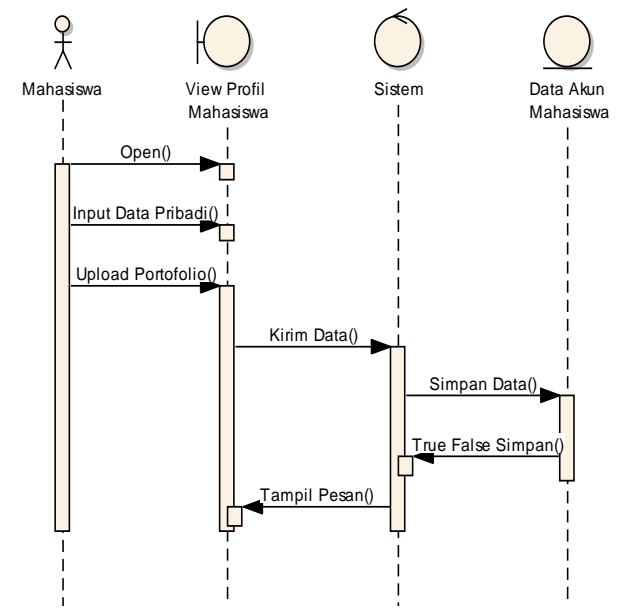

Gambar 12. Sequence Diagram Melengkapi Data Akun Mahasiswa

\subsection{Implementasi Sistem}

4.4.1 Implementasi Perangkat Lunak Tampilan Mahasiswa

4.4.1.1 Implementasi Halaman Login

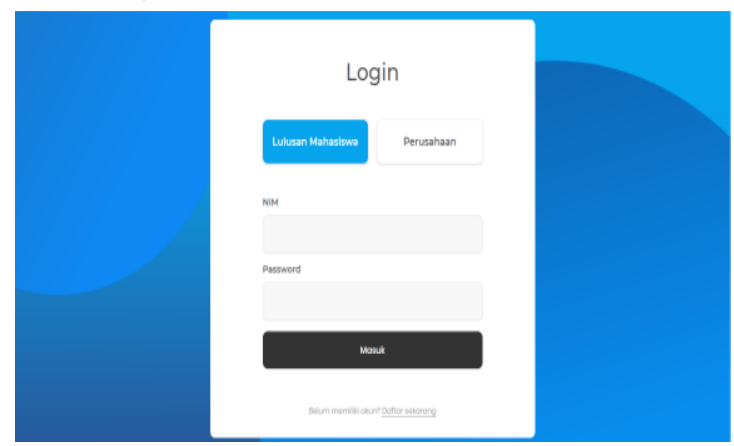

Gambar 13. Halaman Login

\subsubsection{Implementasi Halaman Utama Lulusan Mahasiswa}

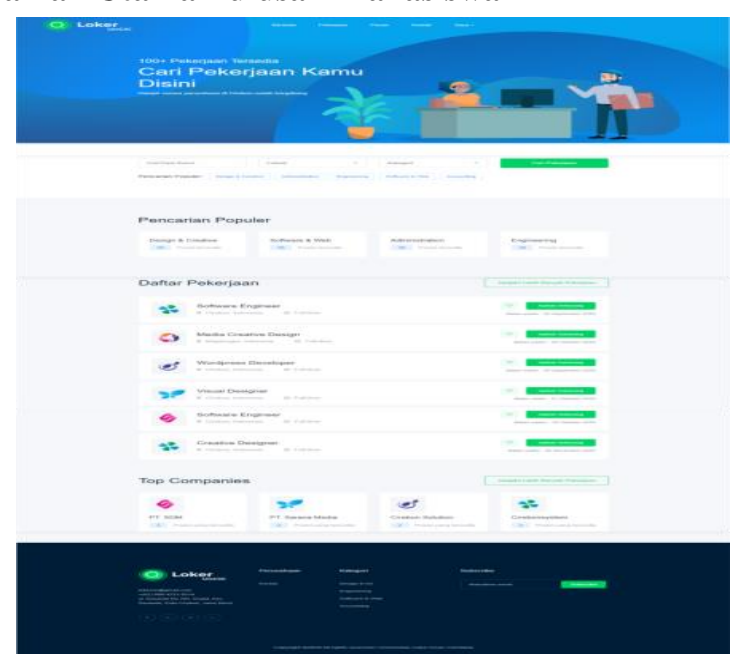

Gambar 14. Halaman Utama Lulusan Mahasiswa

Sistem Aplikasi Lowongan Kerja Lulusan Mahasiswa CIC Pada Universitas Catur Insan Cendekia Kota Cirebon Berbasis Website I - (Indrayansyah, Linda Norhan, Wiwiek Nurkomala Dewi) 
4.4.1.3 Implementasi Pekerjaan

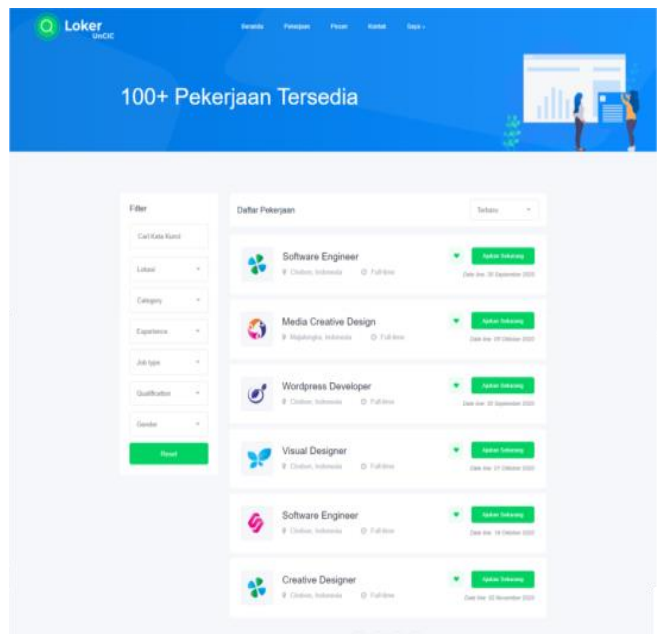

Gambar 15. Pekerjaan

4.4.1.4 Implementasi Pesan Undangan
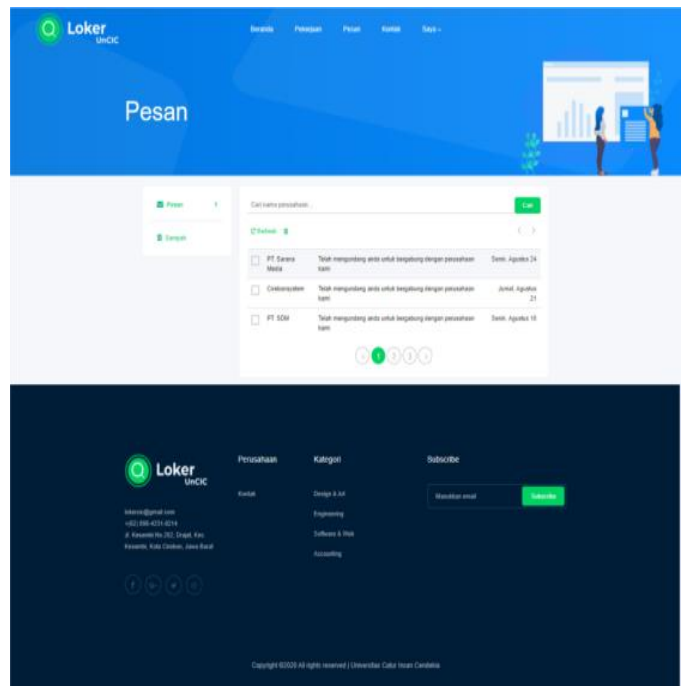

Gambar 16. Pesan Undangan

4.4.1.5 Implementasi Isi Pesan Undangan

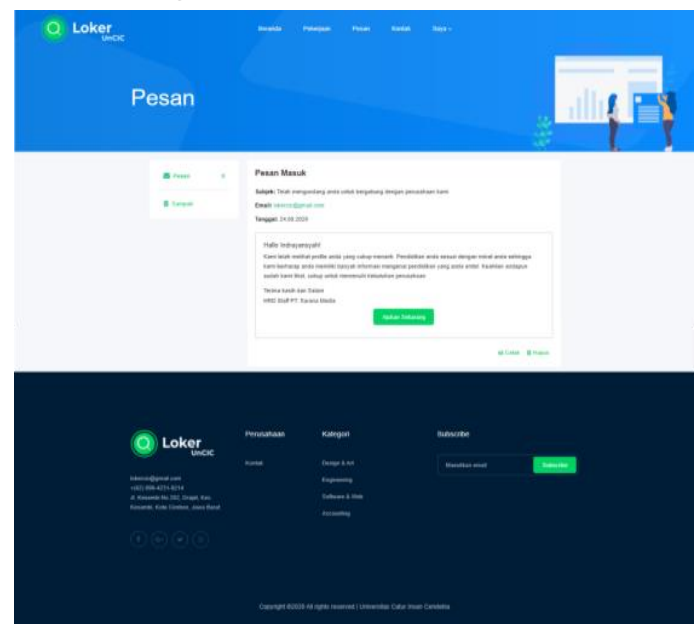

Gambar 17. Isi Pesan Undangan 


\subsubsection{Implementasi Profil}

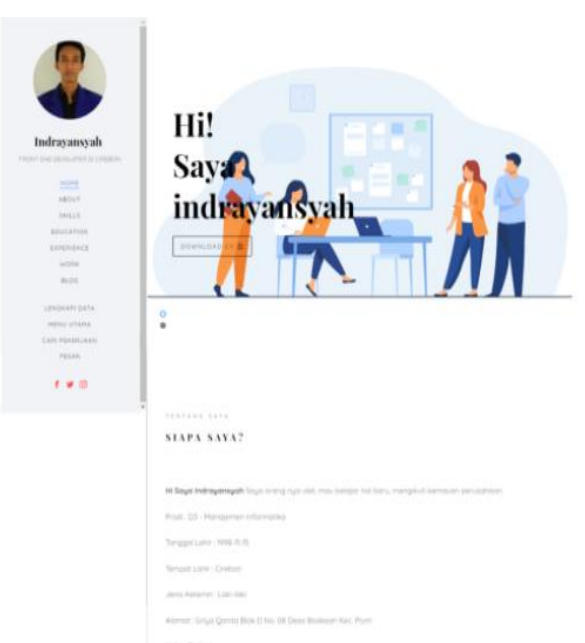

Gambar 18. Profil

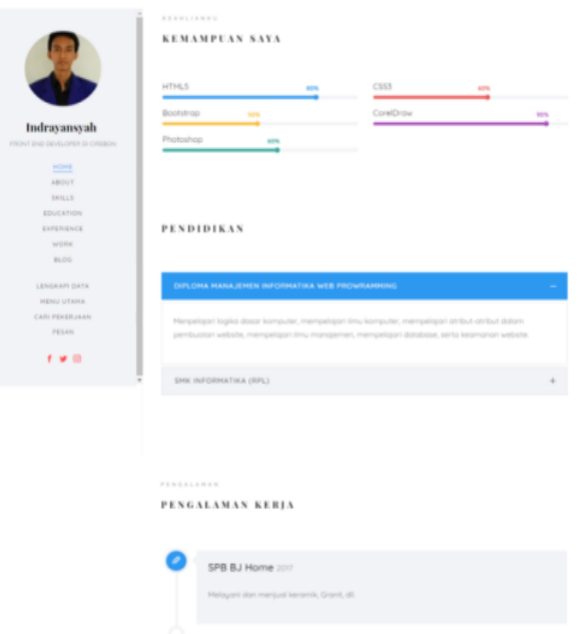

Gambar 19. Profil Lanjutan 1

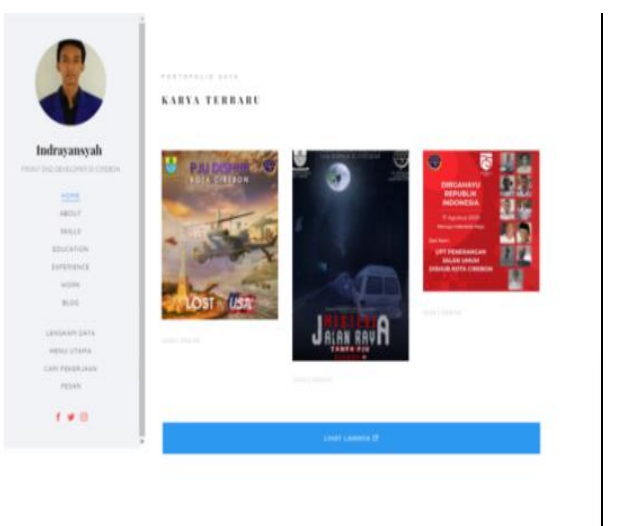

Gambar 20. Profil Lanjutan 2

Sistem Aplikasi Lowongan Kerja Lulusan Mahasiswa CIC Pada Universitas Catur Insan Cendekia Kota Cirebon Berbasis Website I - (Indrayansyah, Linda Norhan, Wiwiek Nurkomala Dewi) 
4.4.1.7 Implementasi Lengkapi Data

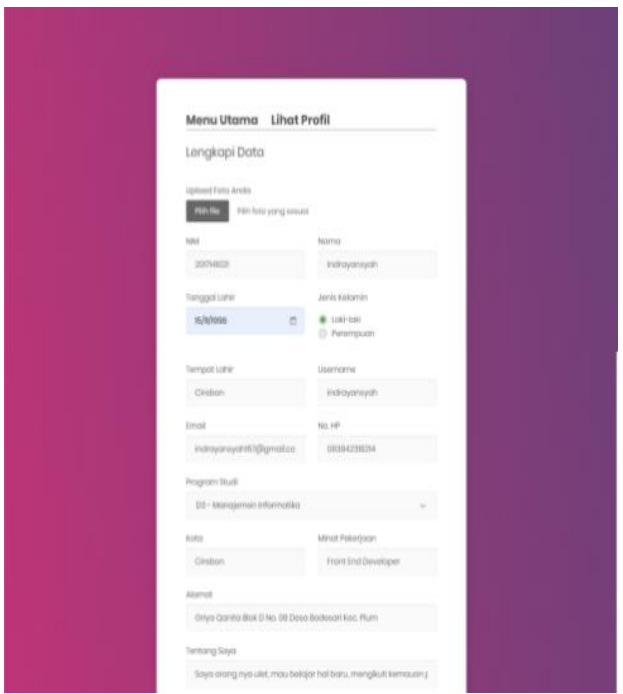

Gambar 21. Lengkapi Data

\subsubsection{Implementasi Portofolio}

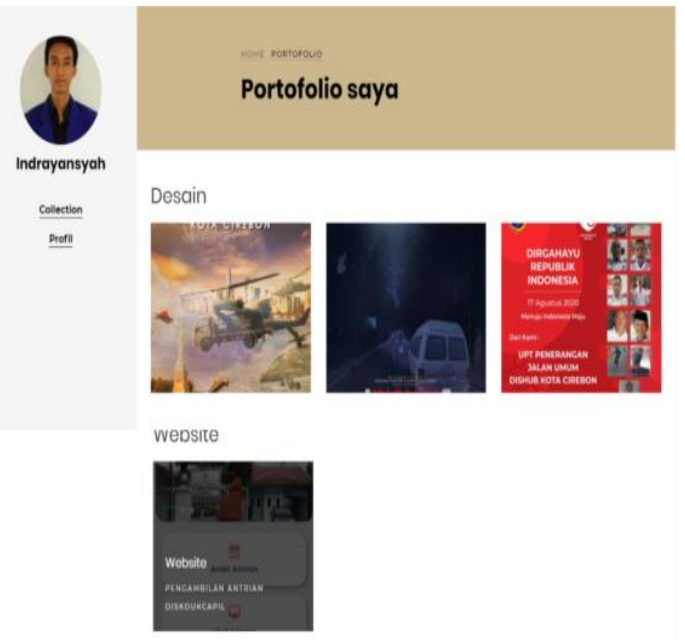

Gambar 22. Portofolio

\subsubsection{Implementasi CV}

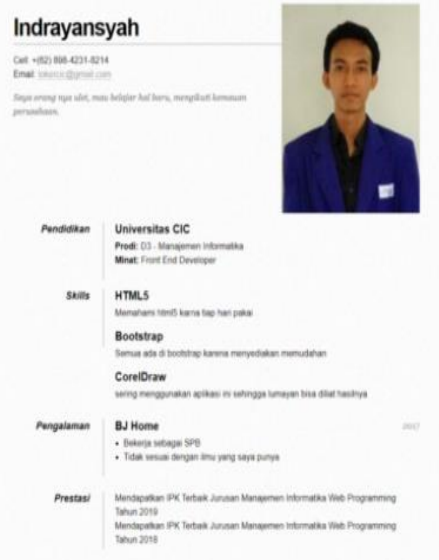

Gambar 23. CV 


\section{KESIMPULAN}

Dengan adanya website ini lulusan mahasiswa dengan mudah mendapatkan informasi lowongan pekerjaan yang tersedia, untuk membuat $\mathrm{CV}$ sudah disediakan form pengisian, dengan adanya sistem ini lulusan mahasiswa sudah dapat memiliki CV, menyediakan media yang dapat menyimpan portofolio sehingga mempermudah melamar pekerjaan langsung melalui website ini yang akan diterima oleh suatu perusahaan. Perusahaan juga dapat mencari kandidat mahasiswa yang diinginkan dengan mudah dan dapat melihat profil mahasiswa sehingga dalam proses mencari perekrutan sesuai kebutuhan perusahaan.

\section{DAFTAR PUSTAKA}

[1] Andriani, T. (2015). "Sistem Pembelajaran Berbasis Teknologi Informasi Dan Komunikasi". 132-133.

[2] Enterprise, J. (2016). "Pengenalan HTML dan CSS". Jakarta: PT Elex Media Komputindo.

[3] Harianto, K., Pratiwi, H., \& Suhariyadi, Y. (2019). "Sistem Monitoring Lulusan Perguruan Tinggi Dalam Memasuki Dunia Kerja Menggunakan Tracer Study". Surabaya: Media Sahabat Cendekia.

[4] Hutahaean, J. (2015). "Konsep Sistem Informasi". Yogyakarta: Deepublish.

[5] Indrajani. (2015). "Database Design". Jakarta: Elex Media Komputindo.

[6] Koesheryatin, \& Suryana, T. (2015). "Aplikasi Internet Menggunakan HTML, CSS dan JavaScript". Jakarta: Elex Media Komputindo.

[7] Media, S. S. (2017). "Jurnal Pendidikan Empirisme": Edisi Desember 2017. 33.

[8] Muslihudin, M., \& Oktafianto. (2016). "Analisis dan Perancangan Sistem Informasi Menggunakan Model Terstruktur dan UML". Yogyakarta: Penerbit Andi.

[9] Sihotang, K. (2019). "Kerja Bermartabat: Kunci Meraih Sukses". Jakarta: Universitas Atma Jaya.

[10] Solichin, A. (2016). "Pemrograman Web dengan PHP dan MySQL". Budi Luhur.

[11] Sudin, S. (2019). "200 Istilah Digital Marketing: Marketer \& Entrepreneur Perlu Pahami". Sukri Sudin.

[12] Susilowati, Y. (2019). "Module E-Commerce - Teaching Factory For Students". Mutiara Publisher.

[13] Dasril Aldo, Nursaka Putra and Zainul Munir, 2019. "Sistem Pendukung Keputusan Penilaian Kinerja Dosen Dengan Menggunakan Metode Multi Attribute Utility Theory ( MAUT )”. Jurnal Sistem Informasi dan Manajemen, Volume7 No. 2 Desember 2019, ISSN 2338-1523E-ISSN 2541-576X.

Sistem Aplikasi Lowongan Kerja Lulusan Mahasiswa CIC Pada Universitas Catur Insan Cendekia Kota Cirebon Berbasis Website I - (Indrayansyah, Linda Norhan, Wiwiek Nurkomala Dewi) 